\title{
Hydraulic resistances of derivation channels of hydropower facilities
}

\author{
Bakhtiyor Uralov ${ }^{1 *}$, Sanatjon Khidirov ${ }^{1}$, Farokhiddin Uljaev ${ }^{1}$, Ikboloy Raimova ${ }^{1}$, \\ Khumoyun Kholmatov ${ }^{1}$, and Alisher Allanazarov ${ }^{1}$ \\ ${ }^{1}$ Tashkent Institute of Irrigation and Agricultural Mechanization Engineers, Tashkent, Uzbekistan
}

\begin{abstract}
Currently, many authors have studied the uniform axisymmetric pressure head laminar and turbulent movement of water in hydraulic smooth and rough (with uniform roughness) pipes of circular cross-section. The results obtained in the study of a plane-parallel turbulent flow in pressure channels allow here only to outline the structure of the corresponding dependencies and to clarify the simplest case of unpressurized fluid movement, when this movement can also be reduced to plane-parallel or, in other words, to movement in channel of infinitely large width with a flat bottom. In all other cases, the only way to solve the problem is experiment. But the possibilities of the experiment are limited, as are limited, and in a number of cases debatable, and the information accumulated to date on the uniform free-flow motion of fluid in channels of various cross-sectional shapes. The unpressurized uniform movement of fluid in channels of various cross-sectional shapes has been completely insufficiently studied. The construction of numerous free-flow watercourses, as well as machine channels of pumping stations, requires scientifically based calculation methods. For the correct establishment of hydraulic calculation methods, a sufficiently deep study of the physical essence of the phenomena occurring in the free-flow derivation channels is necessary. The extensive construction of numerous free-flow watercourses, as well as hydroelectric power plant (HPP) derivation channels, requires scientifically based calculation methods. For the correct establishment of hydraulic calculation methods, a sufficiently deep study of the physical essence of the hydraulic phenomena occurring in the free-flow derivation channels of HPPs is necessary.
\end{abstract}

Keywords: hydropower plants, diversion canals, free-flow canals, hydropower structures, hydraulic resistance.

\section{Introduction}

The question of head losses with uniform steady motion in cylindrical channels - head losses along the length - has more than a century of history. The currently widely used design relationships for determining the Shezy coefficient are based on the assumption that the longitudinal shear stresses acting from the flow on the channel walls are uniformly

\footnotetext{
* Corresponding author: vohidov.oybek02@gmail.com
} 
distributed along the wetted perimeter. Evaluating the acceptability of this assumption for flows with different cross-sections, two different groups of channels can be distinguished.

1st group. The assumption does not accurately correspond to reality, and the error in performing practical calculations is not permissible, however, for a wide range of Reynolds numbers, an adjustment can be made taking into account the geometric features of the shape of the living section, and thereby ensure the required accuracy of calculations. We will say that the channels belonging to the second group have a «correct» shape. As shown by the preliminary analysis, this group for the case of free-flow movement includes, in particular, rectangular, trapezoidal, parabolic, semicircular, which are often found in the practice of hydraulic engineering and hydropower construction, including the derivation channels of hydroelectric power plants.

2 nd group. In the channels of this group, the Weisbach-Darcy formula requires the introduction of adjustments that depend not only on the geometric formula of the channel, but also on the Reynolds number, which makes the use of this formula practically inappropriate. This group includes channels, for example, with a star-shaped cross-section.

In the present work, it is planned to study the head losses along the length during the free-flow movement of water in the channels of the «correct» shape, i.e. in the channels of the first group. Until recently, it was believed that in free-flow derivation channels with a «correct» cross-sectional shape, its influence on the value of pressure losses can always be estimated with an acceptable approximation using the hydraulic radius. However, this position is not always ensured in the case of channels with a «correct» shape, cross-section [1-8]. The authors indicated in the literature have shown that for free-flow channels with a «correct» cross-sectional shape, the hydraulic radius as a parameter that must take into account its effect on the value of pressure losses in these channels is insufficient. The works of a number of authors (both already mentioned and some others [7-14]), it was also shown that the dependencies obtained for calculating the hydraulic resistance in round pressure pipes cannot be extended without appropriate adjustments to gravity channels (subject to replacement in corresponding calculations of the pipe diameter - by the value, where is the hydraulic radius). This position is justified by the presence of a number of factors that distinguish the pressure flow of liquid in pipes from its free flow in channels, where there is a free flow surface, a wider range of roughness of the bottom and walls of the channel, a different (than in pipes) distribution of tangential stresses along the wetted perimeter, the possibility of the existence of two different flow states (depending on the slope of the bottom of the derivation channels). From this, in particular, it follows (and this is confirmed by the data of the corresponding experimental studies published in the literature) that in the case of gravity channels, the pressure loss coefficient, and hence the pressure loss, depend not only on the relative roughness and Reynolds number, but also on the shape of the crosssection of the channel. To calculate the main magnitudes involved in the comparison, the following data were borrowed from Bazin: water temperature, hydraulic radius $\mathrm{R}$ in $\mathrm{cm}$, average flow velocity $v$ in $\mathrm{mm} / \mathrm{second}$, as well as the value $A=R_{i} / v^{2}$, which is a measure of hydraulic resistance. Since «A» is not a dimensionless quantity, it became dimensionless by multiplying by the acceleration of gravity «g».

To move forward in determining the pressure losses in free-flow channels, first of all, it would be necessary to supplement Bazin's experiments by adding to them additional series of accurate observations obtained on smaller models in the course of mathematical measurements and deeply penetrating into the mechanism of the phenomena.

Given in formula (1),

$$
F\left(l_{1}, l_{2}, \Delta, v, F, \rho, G, v\right)=0
$$

and the parameters introduced into equation (1) fall into three categories: 
-characteristic linear dimensions determined by the boundary conditions (standard linear dimension of the free flow section 11, the height of the roughness protrusions $\Delta$ );

-kinematic and dynamic characteristics of movement (average speed $v$, hydraulic resistance force F, gravity G);

-physical properties of the liquid (density $\rho$, viscosity $v$ ).

Dependence (1) can be given a more definite form by grouping all variable dimensional quantities into dimensionless complexes using the $\pi$ - theorem. Bearing in mind that the parameters obtained as a result of the analysis of dimensional values characterizing the uniform flow of fluid in a free-flow channel are: coefficient of hydraulic friction $\lambda$; Reynolds number Re; Froude number $F r$; relative roughness $\frac{\Delta}{R}$; channel shape parameter $\frac{l_{1}}{l_{2}}$. Equation (1) can be represented as:

$$
\lambda=f\left(\frac{l_{1}}{l_{2}} ; \frac{\Delta}{R} ; F_{r} ; R_{e}\right)
$$

or

$$
\lambda=f\left(\Phi ; \frac{\Delta}{R} ; F_{r} ; R_{e}\right)
$$

where, $\Phi=f\left(\frac{l_{1}}{l_{2}}\right)$ - function depending on the shape of the free cross-section of the channel. Naturally, finding the functional dependence of the hydraulic friction coefficient on such a large number of simultaneously acting variables is a difficult task. These variables, depending on the conditions of fluid movement, can affect $\lambda$ to varying degrees. We will consider and compare the hydraulic parameters of a number of water flows in channels with different cross-sectional shapes, using Bazin, carried out in channels of various shapes with different roughness and adding to them additional series of experiments carried out in a channel of rectangular and trapezoidal cross-sectional shapes, made of a sufficiently close to smooth and rough material, operating at a calm state of the flow, in an area close to smooth and rough friction. An analysis of the formulas used so far shows that they are in all cases suitable for determining the head loss. Some parameters that really affect hydraulic resistance are considered passively in these formulas. The disadvantage of these formulas is that they do not take into account the influence on the flow process, in addition to the roughness and Reynolds number, as well as the shape of the free crosssection of the channel. Many researchers really believed, for example, that only the roughness is the most important element of the study when establishing the formula for determining the pressure loss, and in view of this, they tried to determine the value of the roughness coefficient as accurately as possible. Although experiments have shown that it is very difficult to achieve both a perfectly smooth and a rough state of the machine in freeflow channels. Meanwhile, Bazin himself suspected that the discrepancy he discovered between the results in some series of experiments was due to the important, not yet unknown influence of the Reynolds number $R e$ and the shape of the channel cross-section on the pressure loss. It is logical to apply the same approach to non-pressure flow in channels as to flows in pipes, i.e. determine the coefficient of hydraulic friction $\Lambda$ as a function of the Reynolds number Re and the relative roughness, bearing in mind, however, that in this case, for free-flow channels, there will be an additional difficulty due to a 
change in the hydraulic radius and, as a consequence, a change in the relative roughness $\Delta /$ R. A small number of studies carried out for free-flow derivation channels does not allow us to reasonably extend dependence on these channels (4). Apparently, this can only be established as a result of special studies:

$$
\lambda=f(\operatorname{Re} ; \Delta / \mathrm{R})
$$

Hence, the need arises to set up appropriate systematic experiments with free-flow channels on models (not large scales).

In accordance with the task, at one time from 1980 to 2020, in the hydraulic laboratory of the Peter the Great St. Petersburg Polytechnic University (SPbPU), and in the laboratory of the hydraulic machine and the interdepartmental laboratory of the Tashkent Institute of Irrigation and Agricultural Mechanization Engineers (TIIAME), corresponding experiments were carried out on models of free-flow channels of rectangular and trapezoidal crosssection. Also, to fill the experimental data, the corresponding series of Bazin's experiments were used on models of free-flow channels - rectangular, trapezoidal and semicircular cross-sections with different roughness. The channels were investigated with two types of roughness of the bottom and wall surfaces: close to smooth (smooth concrete), and a surface with gravel glued to it $\mathrm{d}=5-7 \mathrm{~mm}$. To carry out these experiments, a large concrete tray of rectangular cross section was used (see Fig. 1). Main dimensions of the tray: length $28.0 \mathrm{~m}$; width $1.51 \mathrm{~m}$ : height $56.5 \mathrm{~cm}$. Food was carried out as follows. From the drainage basin, water was supplied by a centrifugal pump to tank 1 of constant pressure, from there in the further presentation, instead of the expression «model of channels», we will sometimes use the expression «channel» (or tray).

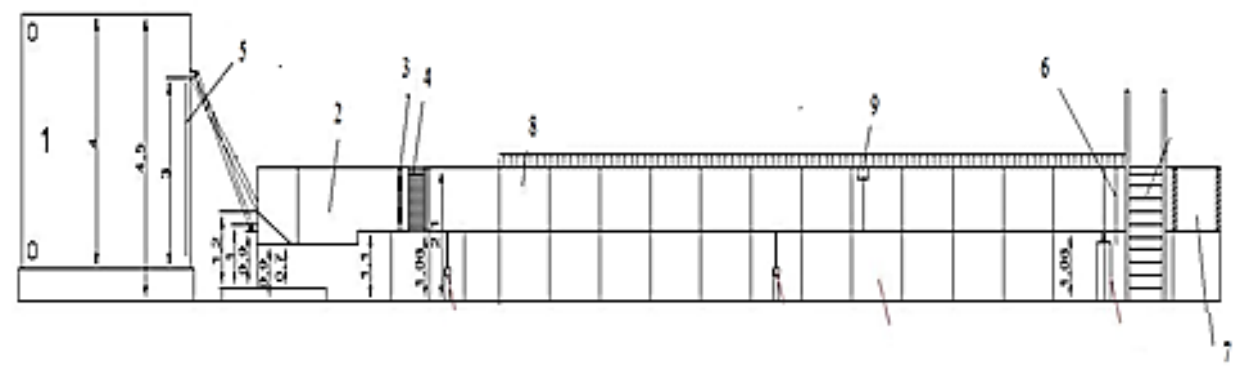

Fig. 1. Schematic of the experimental setup: 1 - constant pressure tank; 2 - stilling tank; 3 - measuring triangular weir; 4 - lattices in the tray; 5 - piezometer; 6 - shutter; 7 - drain channel; 8- experimental channel; 9 - measuring needles.

Water from the constant pressure tank 1 entered the stilling tank 2, and then through the grids (available in the stilling tank to maintain a calm level) into the measuring triangular weir 3 . Then the water entered the test tray 8 (i.e., into the investigated channel), and then through the drain channel 7 back to the pool. The head above the ridge of the weir was determined using a piezometer 5, and reports were made using a measuring needle 9 . The test flume had a constant slope $i=0.001$. The channels taken for the study had the following dimensions: rectangular $b_{g}-1.51$ wide and, trapezoidal - $0.16 \mathrm{~m}$ wide along the bottom with a slope $m=1.732\left(m=\operatorname{ctg} \psi, \psi=30^{\circ}\right)$.

Since until now there are no analytical dependences that fully describe the mechanism of turbulence and are suitable for practical calculations related to the free-flow motion of a liquid, it is necessary to resort to experimental studies [12-20]. Due to the lack of sufficient knowledge about the factors that determine the regularities of fluid movement in free-flow 
channels, as well as derivation channels of hydroelectric power plants, it is assumed that the regularities of flow in circular pressure pipes are also applicable to free-flow channels, if, when calculating them, we have in mind the hydraulic radius, and not the diameter (as it is done in relation to round pipes, with the pressure movement of liquid in the pressure pipelines of a hydroelectric power station).

\section{Methods}

The method for studying this work is the analysis of the operation of the HPP derivation channels in various modes, operating in different hydraulic conditions and different values $h$ - flow depth, $R$ - hydraulic radius and $\chi$ - of the wetted perimeter of the living section of the flow, taking into account the influence of the roughness and shape of the channel on the hydraulic resistance of the derivation channels of the hydroelectric power station.

\section{Results and discussion}

The experimental data obtained showed that the intensity of the influence of the roughness and shape of the channel on the hydraulic resistance of the derivation channels of the hydroelectric power station is directly dependent on the operating mode of the hydroelectric power station. The experimental studies published in the literature, carried out in order to clarify the above assumption and clarify the above-mentioned regularities in free-flow channels, as well as derivation channels, were carried out at different times and in different conditions, some of their results do not always agree with each other, and the calculated dependences recommended on their basis are very contradictory. In particular, the question of the influence of the roughness and shape of the channel and its dimensions on the regularities of the hydraulic resistance of the derivation channels of hydroelectric power plants is not completely clear [21-28].

When fluid flows in free-flow channels, derivation channels of hydropower structures, a number of factors are added that usually do not occur during pressure flow of liquid in pipelines (where their entire living section is filled with liquid); the presence of a free surface, the existence of suspended materials in the flow, the difference in the shape of the cross-section of the channels from the circular cross-section, the existence of two different states of the flow depending on the slope of the channel, the presence of a wider range of roughness in free-flow channels, derivation channels of HPPs, etc. If the average velocity in a channel with a different correct cross-section is calculated by the usual equation of the average velocity, and in this case will have almost the same form, then it can be found that the expressions for the average velocity in this case will have almost the same form as the expressions obtained for average speed in the channel for a trapezoidal section (equations (5) and (6));

$$
\begin{gathered}
v / v_{*}=a_{g l}-b+b \ln \left(R v_{*} / v\right)+b \Phi-\bar{\kappa} v / v_{*} \\
v / v_{*}=a_{s h}-b+b \ln (R / \Delta)+b \Phi-\bar{\kappa} \nu / v_{*}
\end{gathered}
$$

only $\Phi$ and $\bar{\kappa}$ depending on the geometry of the channel cross-section, they will change (from section to section). In view of the above, equations (5) and (6) can be considered rational equations for determining the average flow velocity in channels with a constant cross section and slope.

If these general equations are compared with the corresponding equation for a channel of infinite width (Figs. 2a and b), then one can see that they differ in the presence of terms in $\langle b \phi »$ and $\bar{\kappa} \bar{u} / \bar{u} *$. These terms can be interpreted as reflecting the combined effect of 
the presence of a free surface and a non-uniform distribution of shear stresses on the bottom and walls of the channel on the head loss.

a)

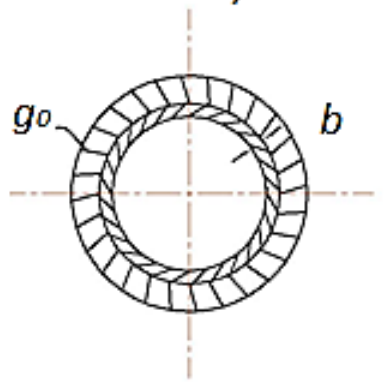

b)

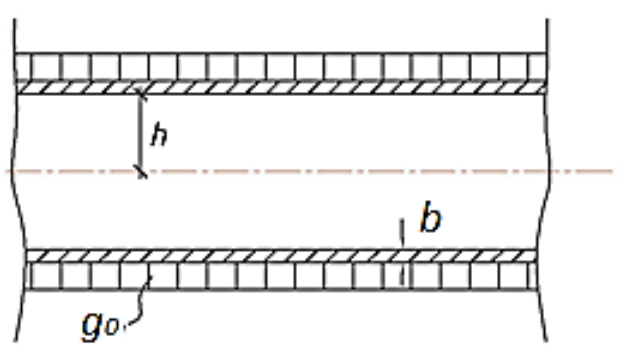

Fig. 2. Distribution of shear stresses: a) in round; b) in wide rectangular pipes and channels

On the other hand, the indicated general equations (5) and (6) make it possible to find the magnitude of the error in determining the pressure loss that would occur if the terms are odd $\langle b \phi »$ and $\bar{\kappa} \nu / \nu *$. The term $\langle b \phi »$ can be calculated for any given shape of the channel cross-section, since it is determined only by its geometry. Calculation according to Kelegan and according to our method shows that in the channels of triangular cross-section the value $" \Phi$ » does not depend on the depth of the water, and in this case $\Phi=0.19$. For channels of rectangular cross-section, the expression for $" \Phi »$ takes the form:

$$
\phi=\ell n\left(1+2 h / B_{0}\right)-h / B_{0}
$$

For ducts with a semicircular cross-section:

$$
\varphi=\int_{0}^{h}\left[\ln \left(\frac{y}{R}\right)\right] \frac{B_{0}}{R} \frac{d y}{\chi}+1.0
$$

To find the value $\bar{K}$ it will probably be necessary to introduce some parameter expressing the ratio of the transverse dimension of the free flow surface in the channel to the wetted perimeter. Quite possibly the best way $\bar{K}$ can be found from experiments. However, as follows from equations (5) and (6), before carrying out these experiments, the characteristics of the bottom and walls of the channel must be determined in advance (also from experiments - preferably with very wide channels of rectangular cross-section).

According to our method and according to the method of G. Kelegan, the formulas of the hydraulic resistance for the trapezoidal derivation channels and other forms of the correct cross-section can be represented as:

$$
\frac{1}{\sqrt{\lambda}}=\frac{1}{\bar{\chi} \sqrt{2}}\left(\ln \frac{\eta_{\Lambda} R}{\delta_{\Lambda}}-1+\ln \frac{h}{\eta_{\Lambda} R}-\frac{\xi h^{2}}{4 \omega}\right)
$$

The same ratio is obtained according to V.T. Chow for channels of a curved transverse profile. In relation to (9) received: $\bar{\chi}$ - Karman's constant [3]; $\bar{\chi}=0.4, \eta_{\Lambda}$ - Reynolds number.

For a viscous sublayer, $\eta_{\Lambda}=\delta_{\Lambda} v_{*} / v ; \delta_{\Lambda}$ - thickness of the viscous sublayer; $h-$ filling the channel; $\xi$ - channel shape function in relation $b(y)=\chi-\xi y ; \chi$-wetted perimeter; $\omega$ - free area of the channel. 
Formula (9) is valid for both fluid motion in smooth $\left(\eta_{\Lambda}=1 / 9\right)$, and in rough channels ( $\eta_{\Lambda}=1 / 30$, moreover $\left.\eta_{\Lambda}=\delta_{\Lambda} / \Delta \ni\right)$. The third and last terms in this formula take into account the influence of the shape of the free cross-section of the channel on its hydraulic resistance. However, formula (9) does not fully take into account the influence of the free surface on the distribution of velocities and head losses. Bearing this in mind and some other assumptions made when deriving formula (9), it should be assumed that formula (9) only allows us to outline the general form of the terms that determine the dependence of the hydraulic resistance of the derivation channel on the shape of its open section. The specific form of the corresponding dependence can be established only from consideration of the corresponding experimental data for the free-flow derivation channels of the hydroelectric power station, with the turbulent motion of the liquid.

To move forward in determining the pressure losses in free-flow channels, it would first of all be necessary to supplement Bazin's experiments by adding to them additional series of accurate observations obtained on smaller models in the course of mathematical measurements and deeply penetrating the mechanism of hydraulic phenomena.

The author's experiments, series № 3a (see Fig. 3); trapezoidal channel; the surface of the bottom and walls of the channel - smooth-graded concrete; $b_{g}=0.161 \mathrm{~m} ; \mathrm{m}=$ $1.732 ; i=1.0 \cdot 10^{-3} ; T 0=16,20 ; v=1.1 \cdot 10-6 \mathrm{~m} 2 / \mathrm{s} ; \Delta_{\ni}=5.6 \cdot 10^{-4} \mathrm{~m}$.

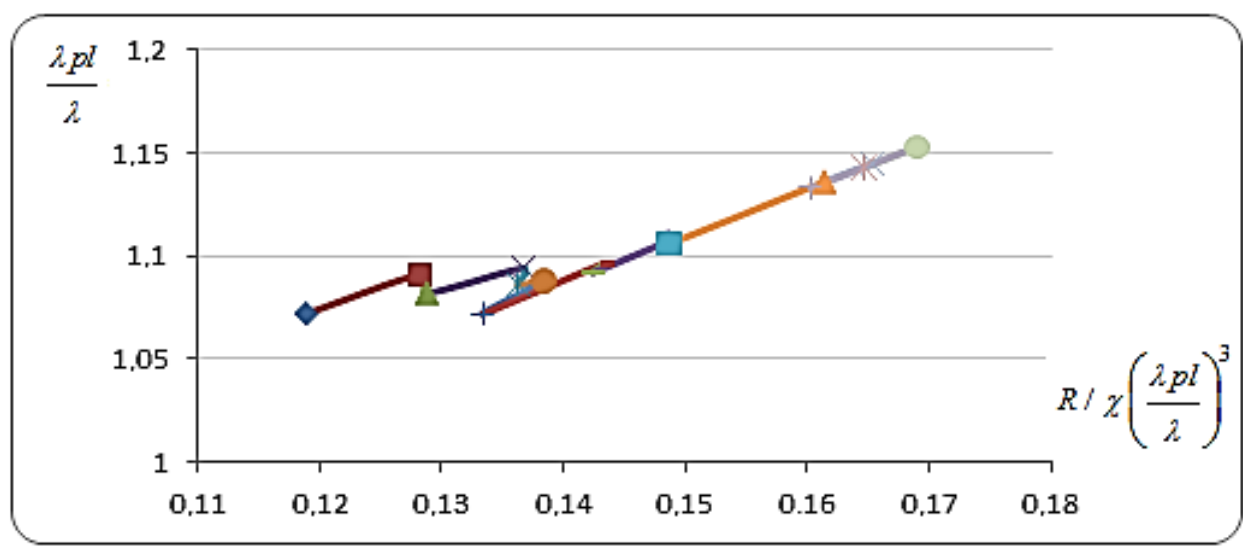

$$
\text { Fig. 3. Dependence } \frac{\lambda p l}{\lambda}=f\left[R / \chi\left(\frac{\lambda p l}{\lambda}\right)^{3}\right] \text {. }
$$

The author's experiments, series № 3b (see Fig. 4); trapezoidal channel; channel bottom and walls - gravel; $d=5-7 \mathrm{~mm} ; b_{g}=0.161 \mathrm{~m} ; m=1.732 ; i=1.0 \cdot 10^{-3} ; T^{0}=16.2^{0}$; $v=1.1 \cdot 10^{-6} \mathrm{~m} 2 / \mathrm{s} ; \Delta \ni=5.8 \cdot 10^{-3} \mathrm{~m}$. 


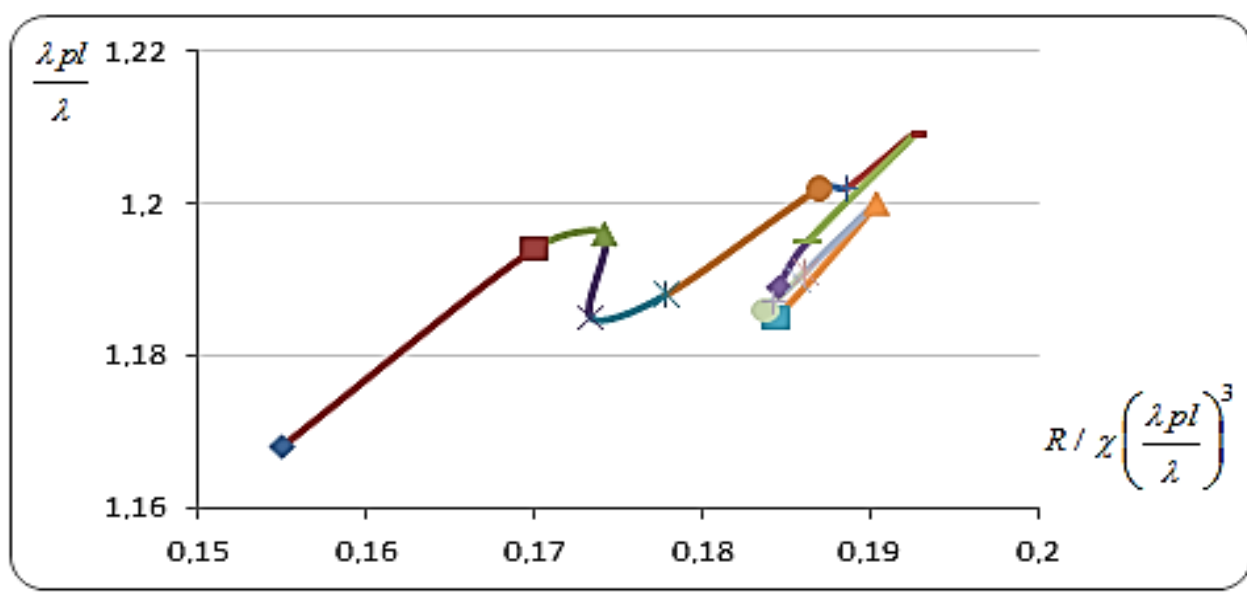

Fig. 4. Dependence $\frac{\lambda p l}{\lambda}=f\left[R / \chi\left(\frac{\lambda p l}{\lambda}\right)^{3}\right]$.

The author's experiments, series № 2a (see Fig. 5); rectangular channel; channel bottom and walls - gravel; $d=5-7 \mathrm{~mm} ; b_{g}=1.52 ; i=1.0 \cdot 10^{-3} ; T^{0}=19.4^{0} ; v=1.02$. $10^{-6} \mathrm{~m} 2 / \mathrm{s} ; \Delta_{\ni}=7.5 \cdot 10^{-3} \mathrm{~m}$.

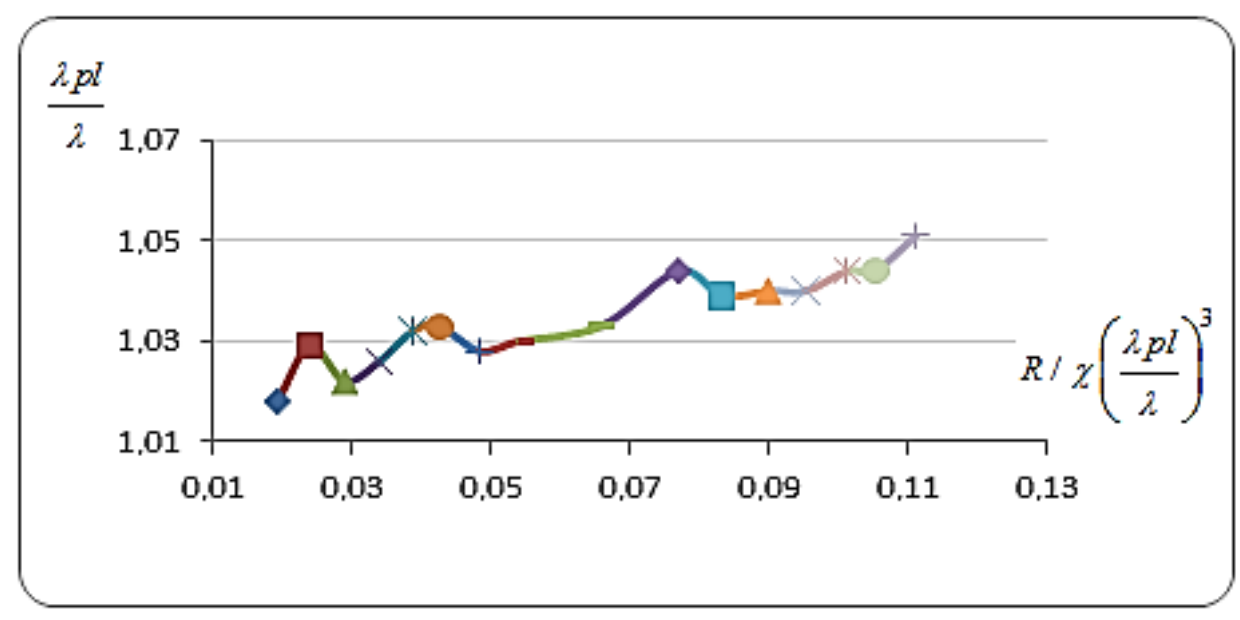

Fig. 5. Dependence $\frac{\lambda p l}{\lambda}=f\left[R / \chi\left(\frac{\lambda p l}{\lambda}\right)^{3}\right]$

The author's experiments, series № 1 (see Fig. 6); rectangular duct; the surface of the bottom and walls of the channel - smooth concrete; $b_{g}=1.51 \mathrm{~m} ; i=1.0 \cdot 10^{-3} ; \mathrm{T}=$ $20^{0} ; v=1.0 \cdot 10^{-3} \mathrm{~m} 2 / \mathrm{s} ; \Delta_{\ni}=7.2 \cdot 10^{-4} \mathrm{~m}$. 


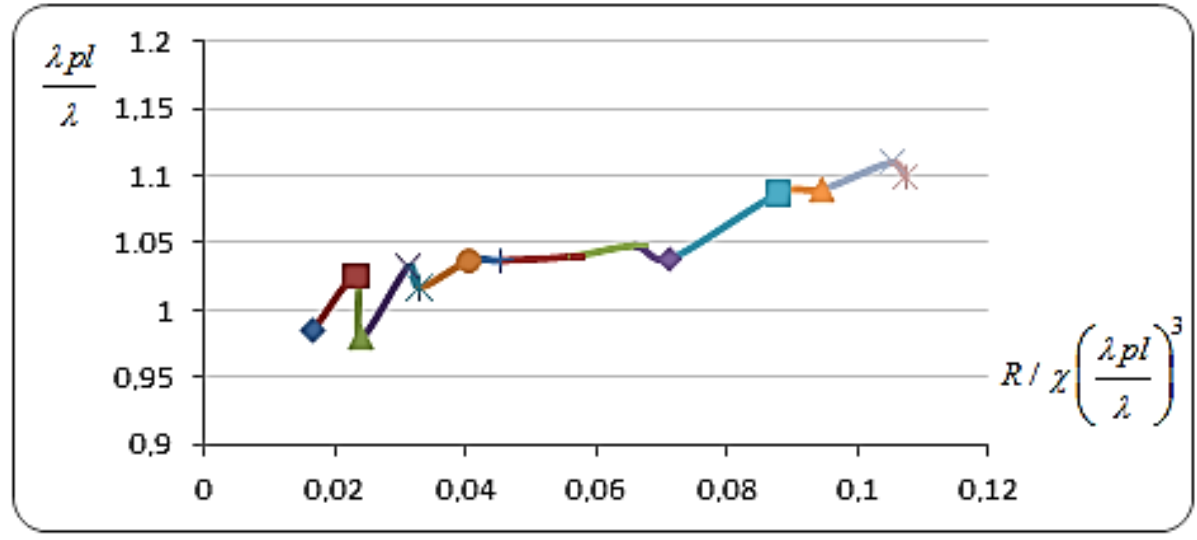

Fig. 6. Dependence $\frac{\lambda p l}{\lambda}=f\left[R / \chi\left(\frac{\lambda p l}{\lambda}\right)^{3}\right]$

Bazin's experiments, series number 27 (see Fig. 7); semicircular channel; channel bottom and walls - gravel; $d=0.01-0.02 \mathrm{~m}: b_{g}=1.23 \mathrm{~m} ; i=1.5 \cdot 10^{-3} ; T^{0}=12^{0} ; v=$ $1.23 \cdot 10^{-6} \mathrm{~m} 2 / \mathrm{s} ; \Delta_{\ni}=11 \cdot 10^{-3} \mathrm{~m}$.

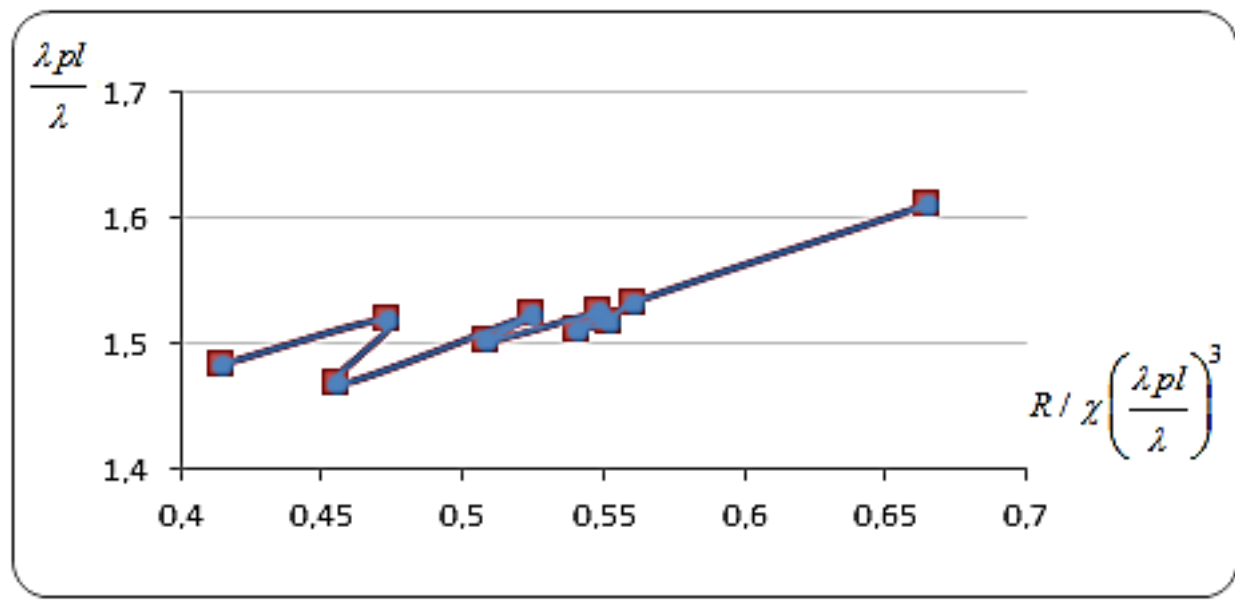

Fig. 7. Dependence $\frac{\lambda p l}{\lambda}=f\left[R / \chi\left(\frac{\lambda p l}{\lambda}\right)^{3}\right]$

Whence for the quantity $\lambda$ the following dependence is obtained $\frac{\lambda p l}{\lambda}=f\left[R / \chi\left(\frac{\lambda p l}{\lambda}\right)^{3}\right]$

(6), in the form of a cubic equation, where $\lambda$ - desired coefficient of hydraulic friction; $\lambda p l$ - coefficient of flat flow hydraulic friction; $R$ - hydraulic radius; $\chi$ - wetted perimeter.

Cubic equation (6) can be resolved relative to the value at known values $\lambda p l, R$ and $\chi$. 


\section{Conclusions}

1. For pressure flow in a round pipe $(R=D / 4)$ and infinitely wide rectangular ducts (at $b » h ; R=h)$, as well as in the derivation channels of the hydroelectric power station, where there is a uniform distribution of shear stresses $\left(\tau_{0}\right)$ along the entire wetted perimeter $\left(\tau_{0} \approx\right.$ $\tau_{\text {осp }}$ ), the geometric interpretation of the hydraulic radius is justified, in other cases (where $\left.\tau_{0} \neq \tau_{o c p}\right)$ - the interpretation of the hydraulic radius $R$, which takes into account both the shape of the free section, is not justified.

2. The free-flow derivation channel of a hydroelectric power station of the correct crosssection corresponds to the law of hydraulic resistance, determined by the shape of the free cross-section « $\Phi$ » and «K» - taking into account the influence of the free surface of the flow during the free-flow movement of water in the diversion channels of hydroelectric power plants.

\section{References}

1. B. Uralov, R. Choriev, L. Maksudova,A. Shernaev, P. Nurmatov, Substantiation of the influence of the channel shape and the roughness of machine canals on the pressure loss of irrigation pumping stations, IOP Conference Series: Materials Science and Engineering, 1030(1), (2021)

2. B. Uralov, S. Khidirov, F. Artykbekova, B. Shodiev, Influence of the roughness and shape of the canal of trapezoidal canals on the pressure loss of hydropower structures, Lecture Notes in Civil Engineering, 141, 35-46, (2021)

3. B. Uralov, D. Saidkhodjaeva, U. Kurbonova, R. Baymanov, Influence of the shape of the pressureless trapezoidal channel and roughness on the pressure loss of the machine channels of the pumping stations, IOP Conference Series: Materials Science and Engineering, 883(1), (2020)

4. D. Bazarov, N. Vatin, B. Obidov, O. Vokhidov, Hydrodynamic effects of the flow on the slab of the stand in the presence of cavitation, IOP Conf. Ser. Mater. Sci. Eng. ,1030, (2021)

5. B. Uralov, K. Isabaev, F. Jamolov, M. Akhmadi, M. Mirzaev, The influence of the shape the living section of the pressureless machine channel and the roughness of its wetted surface on the hydraulic resistance, IOP Conference Series: Materials Science and Engineering, 883(1), (2020)

6. D. Bazarov, I. Markova, B. Norkulov, O. Vokhidov, Hydraulic aspects of the layout of head structures during water intake from lowland rivers, IOP Conf. Ser. Mater. Sci. Eng., 1015, (2021)

7. D. Bazarov, I. Markova, S. Sultanov, F. Kattakulov, Dynamics of the hydraulic and alluvial regime of the lower reaches of the Amudarya after the commissioning of the Takhiatash and Tuyamuyun hydrosystems, IOP Conf. Ser. Mater. Sci. Eng., 1030, (2021)

8. D. Bazarov, O. Vokhidov, Extinguishing Excess Flow Energy in Spillway Structures, in Proceedings of EECE 2020, LNCE 150, 535-545, (2021) DOI: 10.1007/978-3-03072404-7_52

9. D. Bazarov, I. Markova, B. Norkulov, K. Isabaev, M. Sapaeva, Operational efficiency of water damless intake, IOP Conf. Ser. Mater. Sci. Eng., 869(7), 072051, (2020)

10. B. Obidov, O. Vokhidov, D. Tadjieva, U. Kurbanova, A. Isakov, Hydrodynamic effects on the flow elements of the downstream devices in the presence of cavitation, IOP Conf. Ser. Mater. Sci. Eng., 1030, 012114 (2021) 
11. D. Bazarov, B. Norkulov, O. Vokhidov, F. Uljaev, Z. Ishankulov, Two-dimensional flow movement in the area of protective regulatory structures, IOP Conf. Ser. Mater. Sci. Eng., 890, (2020)

12. A. Krutov, R. Choriev, B. Norkulov, D. Mavlyanova, A. Shomurodov, Mathematical modelling of bottom deformations in the kinematic wave approximation, IOP Conf. Ser. Mater. Sci. Eng., 1030, (2021)

13. A. Krutov, B. Norkulov, F. Uljaev, F. Jamalov, Results of a numerical study of currents in the vicinity of a damless water intake, IOP Conf. Ser. Mater. Sci. Eng., 1030, (2021)

14. A. Krutov, B. Norkulov, D. Mavlyanova, Simulation of spreading of non-conservative passive substances in water bodies, IOP Conf. Ser. Mater. Sci. Eng., 883(1), 012028 (2020)

15. B. Matyakubov, I. Begmatov, I. Raimova, G. Teplova, Factors for the efficient use of water distribution facilities, IOP Conf. Ser. Mater. Sci. Eng., 883, (2020)

16. B. Uralov, N. Rakhmatov, S. Khidirov, F. Uljaev, I. Raimova, Hydraulic modes of damless water intake, IOP Conf. Ser. Mater. Sci. Eng., 1030(1), (2021)

17. D. Bazarov, I. Markova, I. Raimova, Sh. Sultanov, Water flow motion in the vehicle of main channels, IOP Conf. Ser. Mater. Sci. Eng., 883, (2020)

18. A. Krutov, B. Norkulov, P. Nurmatov, M. Mirzaev, Applicability of zero-dimensional equations to forecast nonconservative components concentration in water bodies, IOP Conf. Ser. Mater. Sci. Eng., 883(1), (2020)

19. A. Krutov, B. Norkulov, F. Artikbekova, P. Nurmatov, Optimal location of an intake at a reservoir prone to salt diffusion, IOP Conf. Ser. Mater. Sci. Eng., 869(7), 072020, (2020)

20. B. Shokirov, B. Norkulov, Kh. Nishanbaev, M. Khurazbaev, B. Nazarov, Computer simulation of channel processes, E3S Web of Conferences, 97, (2019)

21. M. Shomayramov, B. Norkulov, J. Rakhmanov, D. Tadjiyeva, J. Suyunov, Experimental researches of hydraulic vacuum breakdown devices of siphon outlets of pumping stations, E3S Web of Conferences, 97, (2019)

22. S. E. Bednaruk, V. V. Chukanov, E. M. Klenov, D. V. Kozlov, Accounting for the Thermal State of the Sayano-Shushenskaya Dam to Determine the Safe Maximum Water Levels in the Reservoir in Developing Its Dispatch Schedules, Power Technology and Engineering, 54 (4), 451-455, (2020)

23. D. Kozlov, A. Yurchenko, The role of inspection of hydraulic structures in the assessment of their technical condition, IOP Conference Series: Materials Science and Engineering, 883(1), 012049, (2020)

24. E. V. Baranov, A. P. Guryev, N. V. Khanov, Recommendations for Hydraulic Calculations of Anti-Erosion Lining with the Use of Spatial Geogrid with Coarse Fragmental Soil, Power Technology and Engineering, 53 (5), 553-556, (2020)

25. A. R. Khafizov, F. F. Kamaletdinov, A. B. Yakushkina, I. V. Nedoseko, Construction regulatory systems to protect the banks of the Ufa river in the area of Ufa water intake, Izvestiya KGASU, 1(51), 118-127, (2020).

26. R. Kh. Mukhametrakhimov, I. R. Aliullova, Improvement of the quality control system for expansion joints with rubber compensators during the repair of bridge constructions, Izvestiya KGASU, 3(53), 47-55 (2020)

27. R. Kh. Mukhametrakhimov, A. A. Panchenko, Features of the quality control system for the construction of outdoor water supply and sewerage networks, Izvestiya KGASU, 4(42), 360-367 (2017)

28. R. Kh. Mukhametrakhimov, A. A. Panchenko, Features of technology of installation and quality control of pipelines with polyfoam polyethylene insulation, Izvestiya KGASU. 2 (44), 246-254 (2018) 